Utah State University

DigitalCommons@USU

\title{
An Interdisciplinary Research Agenda for the Study of Ecological- Economic Systems in the American West
}

Amitrajeet A. Batabyal

Utah State University

Follow this and additional works at: https://digitalcommons.usu.edu/eri

\section{Recommended Citation}

Batabyal, Amitrajeet A., "An Interdisciplinary Research Agenda for the Study of Ecological-Economic Systems in the American West" (2000). Economic Research Institute Study Papers. Paper 189.

https://digitalcommons.usu.edu/eri/189

This Article is brought to you for free and open access by the Economics and Finance at DigitalCommons@USU. It has been accepted for inclusion in Economic Research Institute Study Papers by an authorized administrator of DigitalCommons@USU. For more information, please contact digitalcommons@usu.edu.

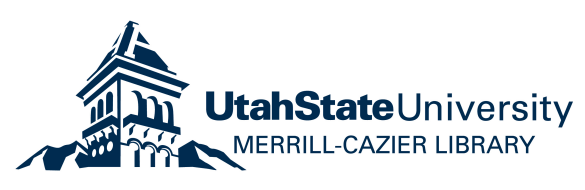


Economic Research Institute Study Paper

ERI \#2000-13

\title{
AN INTERDISCIPLINARY RESEARCH AGENDA FOR THE STUDY OF ECOLOGICAL-ECONOMIC SYSTEMS IN \\ THE AMERICAN WEST
}

\author{
by \\ AMITRAJEET A. BATABYAL \\ Department of Economics \\ Utah State University \\ 3530 Old Main Hill \\ Logan, UT 84322-3530
}

April 2000 


\title{
AN INTERDISCIPLINARY RESEARCH AGENDA FOR THE STUDY OF ECOLOGICAL-ECONOMIC SYSTEMS IN
}

THE AMERICAN WEST

\author{
Amitrajeet A. Batabyal, Associate Professor \\ Department of Economics \\ Utah State University \\ 3530 Old Main Hill \\ Logan, UT 84322-3530
}

The analyses and views reported in this paper are those of the author(s). They are not necessarily endorsed by the Department of Economics or by Utah State University.

Utah State University is committed to the policy that all persons shall have equal access to its programs and employment without regard to race, color, creed, religion, national origin, sex, age, marital status, disability, public assistance status, veteran status, or sexual orientation.

Information on other titles in this series may be obtained from: Department of Economics, Utah State University, 3530 Old Main Hill, Logan, Utah 84322-3530.

Copyright (C) 2000 by Amitrajeet A. Batabyal. All rights reserved. Readers may make verbatim copies of this document for noncommercial purposes by any means, provided that this copyright notice appears on all such copies. 


\title{
AN INTERDISCIPLINARY RESEARCH AGENDA FOR THE STUDY OF ECOLOGICAL-ECONOMIC SYSTEMS IN \\ THE AMERICAN WEST
}

\section{Amitrajeet A. Batabyal}

\begin{abstract}
Increased public awareness of resource management issues and new attitudes toward resource conservation have led to great interest in the subject of the apposite use and management of natural and environmental resources in the American west. This paper analyzes this subject from an interdisciplinary ecological-economic perspective. The paper first identifies and then discusses four salient issues concerning the study of the west's ecological-economic systems that remain inadequately understood. Next, the paper proposes a research agenda that will enable us to shed light on some key questions concerning the functioning, health, and management of the west's ecological-economic systems.

JEL classification: Q20, C61, D81
\end{abstract}

Key words: American West, ecological-economic system, interdisciplinary research agenda 


\section{AN INTERDISCIPLINARY RESEARCH AGENDA FOR THE STUDY OF ECOLOGICAL-ECONOMIC SYSTEMS IN \\ THE AMERICAN WEST ${ }^{1}$}

\section{Introduction}

There is no gainsaying the fact that natural and environmental resources are an important part of life in the American west. Grazing, ranching, mining, and recreational activities such as camping, fishing, and hunting have all been and are a salient part of the lives of people residing in the states comprising the American west. With increasing use of these resources, federal and state governments have established a plethora of rules and regulations governing the use and the management of western natural and environmental resources. As a result, the nature of the regulatory relationship between the regulating and the regulated parties has changed substantially over time (Clawson, 1983, p. 2). Further, as Cawley (1993) has noted, increased public awareness of resource management issues and new attitudes toward resource conservation have combined to dramatically alter the character of this regulatory relationship.

This increased public awareness and the rise of new attitudes toward resource conservation have been accompanied by a remarkable convergence in the views of biological and social scientists regarding the appropriate way in which natural and environmental resources should be viewed, studied, and managed. Today, most ecologists and economists agree that natural and environmental resources should be thought of as ecological-economic systems that are jointly determined. ${ }^{2}$ Once

\footnotetext{
${ }^{1}$ We thank Rod Eggert and an anonymous referee for their helpful comments on a previous version of this paper. We acknowledge financial support form the Utah Agricultural Experiment Station, Utah State University, Logan, UT 84322-4810, by way of project UTA 024 . Approved as journal paper \#7238. The usual disclaimer applies. systems.

${ }^{2}$ As such, in the rest of this paper, we shall refer to natural and environmental resources as ecological-economic
} 
it is recognized that ecological-economic systems are jointly determined, it seems obvious that these systems should be studied as one system (see Perrings et al. (1995a), Dasgupta (1996), Dasgupta and Maler (1997), and Batabyal (1999a, 1999b)). However, because this recognition has been recent, important issues pertaining to the functioning, the health, and the management of jointly determined ecological-economic systems remain inadequately understood. Given this state of affairs, this paper has three objectives. First, we discuss four of these issues in the context of the extant literature. Next, we propose an interdisciplinary research agenda for studying these four issues. Finally, we show how specific aspects of this research agenda might be accomplished.

The four issues of this paper are (i) the substitutability between different types of natural capital, (ii) the effects of economic activities on the health of an ecological-economic system, (iii) the relationship between human activities and the keystone species of an ecological-economic system, and (iv) the optimal management of ecological-economic systems. We now discuss these issues in greater detail.

\section{Four Issues and the Related Literature}

\section{Substitutability Between Different Kinds of Natural Capital}

Two kinds of substitutability are relevant. The first kind concerns the substitutability between natural and produced capital. The second kind relates to the substitutability between different types of natural capital. The substitutability between natural and produced capital has been studied by economists in considerable detail (see Solow (1974), Hartwick (1977, 1978), Dixit et al. (1980), Daly and Cobb (1989), Daly (1991), and Turner (1992)). In contrast, the substitutability between different types of natural capital has received very little attention from ecologists and economists. 
This has led Perrings (1996, p. 232) to note that "the complementarity between species in many [ecological-economic systems] is still very imperfectly understood." Why is it important to understand the substitutability between different types of natural capital? This is because the resilience $^{3}$ of ecological-economic systems is typically a function of this substitutability (see Schindler (1990) and Costanza et al. (1994)).

Consequently, in raising this issue of substitutability, our objective is to point to the questions that require additional research attention. Here are three examples of such questions. What is the relationship between the resilience of an ecological-economic system and the number of substitute species in this system that can perform a given set of ecological functions? What is the minimum combination of resources that will permit an ecological-economic system to function under the expected range of economic and ecological conditions? Finally, what is the effect of incomplete — and possibly incorrect—-knowledge about inter-species substitutability on the decision to conserve biological diversity?

\section{Effects of Economic Activities on the Health} of an Ecological-Eeconomic System

It is no surprise that the level of economic activity tends to have an impact on the health of an ecological-economic system. Population ecologists and resource economists—see Dasgupta (1982), Clark (1990), and Walker (1993) — now agree that excessive levels of economic activity can have a detrimental impact on the health of an ecological-economic system. Given this situation, it is important to examine the impact of the level of economic activity on the health of an ecologicaleconomic system.

\footnotetext{
${ }^{3}$ Resilience refers to "the amount of disturbance that can be sustained [by an ecological-economic system] before a change in system control or structure occurs." (Holling et al., 1995, p. 50).
} 
Put differently, research is needed to analyze the impacts of livelihood based economic activities on the health of an ecological-economic system. From a practical perspective, what this means is that we need to know the answers to three specific questions. First, how does the health of an ecological-economic system evolve when the services that this system provides are utilized at a constant rate over time? Second, how do changes in the pattern of economic activities-associated with changing livelihoods — affect the health of an ecological-economic system? Third, what impacts do economic policies that apply fixed rules in order to achieve constant yields have on the health of an ecological-economic system?

\section{Relationship Between Keystone Species and Human Activities}

As Paine $(1969,1974)$ and Krebs (1985) have noted, the activities of keystone species determine the structure of ecological-economic systems. Unfortunately, economists have contributed very little to our understanding of the nexuses between human activities and keystone species. Consequently, a number of questions involving the link between human activities and keystone species present themselves. In particular, two questions warrant early research attention.

Because the health of an ecological-economic system depends on the welfare of the keystone species in that system, the design of measures of the health of an ecological-economic system should incorporate the activities of keystone species into these measures. This will be a salient task for future researchers. Second, we know from Holling et al. (1995) that in some ecological-economic systems, environmental disturbances can perform the same role as keystone species in maintaining species diversity. Consequently, it will be necessary to study the extent to which human activities can mimic the role played by environmental disturbances. An answer to this question will provide 
useful insights into the ability of humans to replicate the role played by the keystone species of an ecological-economic system.

The Optimal Management of Ecological-

Economic Systems

As noted by Dasgupta (1996) and Batabyal (1999b, 1999c), for too long, ecologists and economists have gone about the task of managing ecological-economic systems in their separate ways. Fortunately, this unhappy state of affairs has begun to change. In particular, recent and ongoing collaborative activities between ecologists and economists have led to a number of new insights into the management of ecological-economic systems (see Perrings et al. (1995b) and Batabyal (1999b)). However, this collaboration has been very recent. Consequently, it is certainly possible to ask meaningful questions about the optimal management of jointly determined ecological-economic systems.

What are some of the most meaningful questions pertaining to the management of ecologicaleconomic systems? In the rest of this section, we focus on three of these questions. The first question concerns the role of time in the management of jointly determined ecological-economic systems. Weninger and Strand (1998) have pointed out that recreational and commercial hunters for most game are subject to seasonal restrictions. Batabyal et al. (1999a, 1999b) have studied the role of time restrictions in the management of rangelands. Batabyal and Beladi (1999) have observed that in most states in the USA, sport fishing seasons exist for a whole host of species. Further, commercial fisheries in Canada, the USA, and in western Europe are subject to a variety of time restrictions. This tells us that today, the use of time restrictions for management purposes is widespread. Despite this, very little is known about the theoretical properties of time based management regimes. As such, 
it is important to study how time based management regimes affect the static and the dynamic behavior of ecological-economic systems. For instance, what effects do time restrictions have on the stock of a resource that is sought to be managed with such restrictions?

Perrings (1995) and Perrings et al. (1995c) have noted that species that are now not keystone species but may become keystone species under different environmental conditions possess insurance value. This observation raises a number of interesting management questions. A question on which there has been virtually no research is the following. How do we design flexible management regimes that will recognize the potential insurance value of some species?

Holling et al. (1995) have noted that if we are interested in maximizing the persistence of the species in an ecological-economic system, then it is important to minimize the likelihood of changes in the various ecological functions. Human activities tend to affect these ecological functions. Further, as Schindler (1990) has noted, some functional groups are represented by a single species. Consequently, it is necessary to design management regimes that pay special attention to the conservation of these single species. The design of such management regimes will be facilitated by analyzing the links between the trinity of the benefits from conservation, the persistence of species, and changes in ecological functions.

Clearly, these questions and their answers are central to the optimal use and management of ecological-economic systems in the American west. Given increased national concern about the sustainable use of the west's ecological-economic systems and the legislative battles over the appropriate use of such systems, it is now more important than ever before to comprehend and manage the west's ecological-economic systems prudently. Such action will ensure that this region's ecology and its economics continues to remain healthy in the near and distant future. 


\section{Previous Research and this Agenda: Two Key Differences}

As indicated in the introductory section, it is only very recently that researchers have begun to study jointly determined, ecological-economic systems. Consequently, there are a number of outstanding issues that require further research attention. The four issues that comprise this paper's research agenda and most of what is currently known about these issues have been discussed in the previous section. Consequently, we now briefly highlight the two key differences between the extant literature on the issues of this paper and the research that we're suggesting be undertaken in the future.

First, until very recently, the existing literature on the four issues of this paper has been marked by a strikingly unidisciplinary perspective. Given the interdisciplinary nature of the American west's resource and environmental problems, the use of such a unidisciplinary perspective has led to the proposal of solutions that have generally failed to address the underlying problems in their entirety. In contrast, the research agenda of this paper is explicitly interdisciplinary in nature.

Second, most of the extant research on the issues of this paper has been conducted in a deterministic framework. Ecologists now recognize that deterministic frameworks do not permit one to adequately understand ecological-economic systems that are characterized by local surprise and continuous environmental perturbations (see Holling (1986), Ives (1995), and Batabyal (1999b)). Consequently, in order to understand the behavior of ecological-economic systems over time and under uncertainty, this paper's research agenda calls for the analysis of such systems in an expressly stochastic framework. We now discuss the methods and the procedures that provide a framework within which the four issues of this paper can be analyzed. 


\section{Proposed Research Methods and Procedures}

The theory of stochastic processes (see Wolff (1989), Ross (1996, 1997), and Batabyal (1998a, 1998b, 1999a)), control theory (see Ross (1983), Clark (1990), and Kamien and Schwartz (1991)), and mechanism design theory (see Kreps (1990), Fudenberg and Tirole (1991)) have all advanced to a point where it is now possible to comprehensively analyze the issues that we discussed in the second section of this paper. Consequently, we propose that the four issues of this paper be studied from a mechanism design/operations research theoretic perspective. This is because the application of this "mechanism design/operations research theoretic approach" to study the four issues of this paper will yield valuable new insights into the functioning, the health, and the management of jointly determined ecological-economic systems.

We now provide two examples that demonstrate the ways in which the mechanism design/operations research theoretic approach can be used to shed light on (i) the effects of economic activities on the health of an ecological-economic system and (ii) the optimal management of ecological-economic systems. In the remainder of this demonstrative section, we shall proxy the health of an ecological-economic system by its resilience. ${ }^{4}$ Further, because rangelands are particularly important ecological-economic systems in the American west, for concreteness, we shall suppose that the ecological-economic system under study is a (publically held) dynamic and stochastic rangeland.

${ }^{4}$ See footnote 4 for a definition of resilience. Although we are thinking of the health of an ecological-economic system in terms of its resilience, these two concepts are not synonymous. In particular, the reader should note that reduced health may lower an ecosystem's resilience. 
The Resilience of a Dynamic and Stochastic

Rangeland

At a particular point in time, this rangeland-mathematically, a semi-Markov process $\{y(t): t \geq 0\}$ - can exist in any one of three possible states. State 1 is the healthy state of the rangeland. In this state forage is plentiful and the rangeland is open for grazing. State 2 is an intermediate state. In this state, forage quality and quantity are lower than in state 1 but the rangeland is not endangered in either an ecological or an economic sense. Consequently, the rangeland is still open for grazing. However, the range manager now monitors the condition of the rangeland more carefully than in state 1 . State 3 is the state in which the rangeland is endangered. In this state, the rangeland vegetation is severely degraded. Consequently, if the manager determines that the rangeland is in state 3 , then no further grazing is permitted. In other words, a time restriction is now in place.

Let us formalize these remarks. As a result of ongoing grazing, ecological/environmental factors (droughts, lack of plant nutrients), and human induced factors (fires), our rangeland stays in state 1 for a mean length of time $\beta_{1}$ and then makes a transition either to state 2 with transition probability $P_{12}$, or to state 3 with transition probability $P_{13}$. When the rangeland is in state 2 , once again because of the previously mentioned reasons, this rangeland will stay in state 2 for a mean length of time $\beta_{2}$ and then move to state 3 with transition probability $P_{23}$. When in state 3 , grazing on this rangeland is terminated. As a result of the termination of grazing, the rangeland vegetation gradually recovers. It is important to note that the rate of recovery depends in part on the extent of rangeland degradation in state 3 . What this means for our purpose is that the length of the recovery period or the length of time during which grazing is not permitted (the time restriction) is itself a random variable. Denote the mean length of the time restriction by $\beta_{3}$. The imposition of this time 
restriction does not guarantee that the rangeland will get back to the most desirable state 1 . Rare events ${ }^{5}$ may interact with the time restriction in a way that results in the rangeland recovering only to the intermediate state 2. To account for these features of the problem, we suppose that as a result of the time restriction, the rangeland returns either to state 1 with transition probability $P_{31}$, or to state 2 with transition probability $P_{32}$. We now use these dynamic and stochastic attributes of this rangeland to derive the resilience of this rangeland in, for instance, state 3.

To derive the resilience of this rangeland in state 3 , it will be necessary to compute the steady state probability of being in state 3. Formally, we are interested in computing $P_{3}=\lim _{t \rightarrow \infty} \operatorname{Prob}\{y(t)=3 / y(0)=j\}$ for any state $j=1,2,3$. In words, given that our rangeland is in state $j$ at time $t=0$, we want to compute the limiting probability, as time tends to infinity, that the rangeland will be in state 3 . To perform this computation, let us denote the limiting probabilities of the embedded Markov chain—see Ross (1996,pp. 213-218; 1997, pp. 379-381)—ofour rangeland by $\pi_{j}, j=1,2,3$. Then, from equation 7.23 in Ross (1997, p. 380) it follows that these limiting probabilities satisfy $\pi_{j}=\Sigma_{\forall i} \pi_{i} P_{i j}$, and $\Sigma_{\forall j} \pi_{j}=1$. Consequently, using the transition probabilities of the rangeland and these two equations, we can calculate the required limiting probabilities. These are given by $\pi_{1}=P_{31} /\left\{1+P_{31}+P_{12} P_{31}+P_{32}\right\}, \quad$ b y $\quad \pi_{2}=\left\{P_{12} P_{31}+P_{32}\right\} /\left\{1+P_{31}+P_{12} P_{31}+P_{32}\right\}, \quad$ a n d $\quad$ b y $\pi_{3}=1 /\left\{1+P_{31}+P_{12} P_{31}+P_{32}\right\}$. Now, to determine the steady state probability of the rangeland being in state $3\left(P_{3}\right)$, let us use equation 7.24 in Ross $(1997$, p. 380). This equation and the limiting probabilities of the embedded Markov chain together tell us that $P_{3}=\beta_{3} /\left\{P_{31} \beta_{1}+\left(P_{12} P_{31}+P_{32}\right) \beta_{2}+\beta_{3}\right\}$.

This steady state probability has a distinct ecological meaning. As discussed in Krebs (1985, p. 587) and Perrings (1998), $P_{3}$ can be thought of as the asymptotic resilience of the rangeland in 
state 3. As indicated previously, resilience is an ecological stability property and it refers to "the amount of disturbance that can be sustained [by a rangeland] before a change in system control or structure occurs" (Holling et al., 1995, p. 50). Note that because the disturbance of particular interest here stems from livestock grazing, and because a change in system control or structure occurs when the rangeland changes state, it makes sense to think of the resilience of the rangeland in state 3 as a measure of its long run health in this state. We have just shown how the proposed operations research theoretic approach of this paper can be used to quantify and thereby study the effect of a particular economic activity (grazing) on the health of a rangeland (ecological-economic system). We now show how this operations research theoretic approach can be used to shed light on the task of optimally managing this dynamic and stochastic rangeland.

The Optimal Management of a Dynamic and Stochastic Rangeland

Continuing with the rangeland example of the previous subsection, it is clear that if we rank the three states from a health perspective, then state 1 is the "healthiest" because forage is plentiful and the rangeland vegetation is not degraded, state 2 is "healthy" because forage quality and quantity are at an intermediate level, and state 3 is "unhealthy" because the rangeland is endangered. In the words of Perrings (1998), states 1 and 2 are "desirable" states and state 3 is the "undesirable" state.

Recall that our range manager terminates grazing on the rangeland if and only if the rangeland is determined to be in state 3 . Further, the mean length of this time restriction is $\beta_{3}$. With these two remarks and the previous paragraph's discussion of the three states in mind, we can now state one possible objective for our range manager. This objective requires the manager to choose the expected length of the time restriction $\beta_{3}$ to minimize the long run probability of being in the 
least desirable state 3 . In words, the range manager attempts to minimize the resilience of the rangeland in the unhealthy or undesirable state. ${ }^{6}$ This is the ecological side of the management picture.

To see the economic side, note that range management results in benefits and costs to society. The benefits stem from the fact that a healthy rangeland will be able to provide society with a flow of consumptive and non-consumptive services. The costs arise from a number of sources. First, it is necessary to have an elaborate bureaucracy in place. Second, the condition of the rangeland needs to be monitored on an ongoing basis. Third, personnel involved in the various tasks associated with management have to be paid. Consequently, in deciding the length of the time restriction, our manager must pay attention to both the benefits and the costs from management. We suppose that because of budgetary and political reasons, ${ }^{7}$ the range manager cannot let the net social benefit from management fall below a certain acceptability threshold. Denote this threshold by $\tilde{B}$. This tells us that the economic side of the manager's problem is given by a constraint on the net social benefit from the time restriction. This constraint is $B\left(\beta_{3}\right) \geq \tilde{B}$, where $B^{\prime}(\cdot)>0$ and $B^{\prime \prime}(\cdot)<0$. In words, the net social benefit function is strictly increasing and strictly concave.

We can now pose the task of range management as an optimization problem. Formally, our manager solves $\min _{\left\{\beta_{3}\right\}} P_{3}=\beta_{3} /\left\{P_{31} \beta_{1}+\left(P_{12} P_{31}+P_{32}\right) \beta_{2}+\beta_{3}\right\}$, subject to $B\left(\beta_{3}\right) \geq \tilde{B}$. In other words, the manager chooses the mean length of time during which the rangeland is closed to grazing (the time restriction) to minimize the resilience of the rangeland in the unhealthy state 3 , subject to the

\footnotetext{
${ }^{6}$ Alternately, the rangeland manger could choose the time restriction to maximize the long run probability of being in the most desirable state. In this way of looking at the problem, the manager chooses $\beta_{3}$ to maximize the health (resilience) of the rangeland in state 1 .

${ }^{7}$ For more on the connections between political factors and range management in the American west, see Davis (1997) and Donahue (1999).
} 
constraint that the net social benefit from management exceed a minimum acceptability threshold. This is a non-linear programming problem with an inequality constraint; as such, it can be solved using standard techniques. Denote the solution to this problem by $\beta_{3}^{*}$.

If the time restriction $\left(\beta_{3}^{*}\right)$ is chosen in this way, then we can be reasonably sure that the rangeland will be healthy in the long run. From an ecological perspective, this means that the resilience of the rangeland in the undesirable state 3 will be low. In economic terms, this means that the rangeland will be able to provide society with a flow of consumptive and nonconsumptive services in the long run.

\section{Expected Results and Conclusions}

In this paper, we have tried to document the merits of a unified approach to the study of jointly determined ecological-economic systems. As the reader will no doubt have noted, we have repeatedly stressed the importance of an approach that pays equal attention to the ecological and to the economic aspects of the problem. Consequently, we believe that the conduct of interdisciplinary research along the lines suggested in this paper will lead to three main results.

First, the stock of theoretical knowledge in ecological economics will increase. The use of the mechanism design/operations research theoretic approach to study western ecological-economic systems is novel. This is at least in part due to the difficulties associated with stochastic modeling. As such, the conduct of research along the lines suggested in this paper will lead to new theoretical insights into the functioning of jointly determined ecological-economic systems in the American west. Further, it is reasonable to suppose that the successful completion of this kind of research will encourage other scholars to engage in research in the new field of ecological economics. 
Second, the proposed research of this paper will improve our understanding of the interdependencies between ecological and economic systems in the American west. As indicated in the second section of this paper, an important research issue concerns the effects of economic activities on the health of an ecological-economic system. Consequently, we expect that the research described in this paper will improve our understanding of the relationships among the inhabitants, the functions, and the services provided by western ecological-economic systems. In the second section of this paper, we had noted that an important issue of this paper concerns the effects of the interactions between human beings and the keystone species of an ecological-economic system. With regard to this issue, the conduct of research along the lines suggested in this paper will shed useful light on the poorly understood relationship between keystone species and human activities. In these ways, this proposed research will improve our understanding of the interdependencies between ecological and economic systems.

Third, by focusing on the management of western ecological-economic systems, this paper's proposed research will shed light on how changes in the health of an ecological-economic system translate into changes in social welfare. The reader will note that in the context of this paper's integrated approach to the management of ecological-economic systems, social welfare is an increasing function of an ecological-economic system's health. In turn, the health of an ecologicaleconomic system depends on the policies that a manager has in place to ensure that the services provided by an ecological-economic system are utilized optimally. Consequently, we expect that this part of the research suggested in this paper will produce results on the systemic effects of alternate management practices. 


\section{References}

Batabyal, A. A. 1998a. On some aspects of ecological resilience and the conservation of species, Journal of Environmental Management, 52, 373-378.

Batabyal, A. A. 1998b. On some aspects of the decision to conserve or harvest old growth forest, Journal of Environmental Management, 54, 15-21.

Batabyal, A. A. 1999a. Species substitutability, resilience, and the optimal management of ecological-economic systems, Mathematical and Computer Modelling, 29, 35-43.

Batabyal, A. A. 1999b. Contemporary research in ecological economics: five outstanding issues, International Journal of Ecology and Environmental Sciences, 25, 143-154.

Batabyal, A. A. 1999c. Aspects of the optimal management of cyclical ecological-economic systems, Ecological Economics, 30, 285-292.

Batabyal, A. A., and Beladi, H. 1999. Time restrictions in natural resource management: a dynamic and stochastic analysis. Unpublished manuscript, Utah State University.

Batabyal, A. A., Biswas, B., and Godfrey, E. B. 1999a. A dynamic and stochastic analysis of the role of time in range management. Unpublished manuscript, Utah State University.

Batabyal, A. A., Biswas, B., and Godfrey, E. B. 1999b. On the choice between the stocking rate and time in range management. Unpublished manuscript, Utah State University.

Cawley, R. M. 1993. Federal Land, Western Anger. University of Kansas Press: Lawrence, USA.

Clark, C. W. 1990. Mathematical Bioeconomics, $2^{\text {nd }}$ edition. John Wiley: New York, USA.

Clawson, M. 1983. The Federal Lands Revisited. Johns Hopkins University Press: Baltimore, USA.

Costanza, R., Kemp, M., and Boynton, W. 1994. Scale and biodiversity in coastal and estuarine ecosystems, in C. Perrrings, K. G. Maler, C. Folke, C. S. Holling, and B. O. Jansson, (Eds.), Biodiversity Loss. Cambridge University Press: Cambridge, UK.

Daly, H. E. 1991. Ecological economics and sustainable development: from concept to policy, Environment Department Working Paper 1991-24, World Bank: Washington, DC, USA.

Daly, H. E., and Cobb, J. B. 1989. For the Common Good. Beacon Press: Boston, USA.

Dasgupta, P. 1982. The Control of Resources. Basil Blackwell: Oxford, UK. 
Dasgupta, P. 1996. The economics of the environment, Environment and Development Economics, $1,387-428$.

Dasgupta, P., and Maler, K. G. 1997. The resource basis of production and consumption: an economic analysis, in P. Dasgupta and K. G. Maler, (Eds.), The Environment and Emerging Development Issues, Volume 1. Clarendon Press Oxford: Oxford, UK.

Davis, C. 1997. Politics and public rangeland policy, in C. Davis, (Ed.), Western Public Lands and Environmental Politics. Westview Press: Boulder, USA.

Dixit, A., Hammond, P., and Hoel, M. 1980. On Hartwick's rule for regular maximin paths of capital accumulation and resource depletion, Review of Economic Studies, 47, 551-556.

Donahue, D. L. 1999. The Western Range Revisited. University of Oklahoma Press: Norman, USA.

Fudenberg, D., and Tirole, J. 1991. Game Theory. MIT Press: Cambridge, USA.

Hartwick, J. M. 1977. Intergenerational equity and the investing of rents from exhaustible resources, American Economic Review, 66, 972-974.

Hartwick, J. M. 1978. Substitution among exhaustible resources and intergenerational equity, Review of Economic Studies, 45, 347-354.

Holling, C. S. 1986. The resilience of terrestrial ecosystems: local surprise and global change, in W. C. Clark and R. E. Munn, (Eds.), Sustainable Development of the Biosphere. Cambridge University Press: Cambridge, UK.

Holling, C. S., Schindler, D. W., Walker, B. W, and Roughgarden, J. 1995. Biodiversity in the functioning of ecosystems: an ecological synthesis, in C. Perrrings, K. G. Maler, C. Folke, C. S. Holling, and B. O. Jansson, (Eds.), Biodiversity Loss. Cambridge University Press: Cambridge, UK.

Ives, A. R. 1995. Measuring resilience in stochastic systems, Ecological Monographs, 65, 217-233.

Kamien, M. I., and Schwartz, N. L. 1991. Dynamic Optimization, $2^{\text {nd }}$ edition. North-Holland: Amsterdam, The Netherlands.

Krebs, C. J. 1985. Ecology, $3^{\text {rd }}$ edition. Harper and Row: New York, USA.

Kreps, D. M. 1990. A Course in Microeconomic Theory. Princeton University Press: Princeton, USA.

Paine, R. T. 1969. A note on trophic complexity and community stability, American Naturalist, 103, 91-93. 
Paine, R. T. 1974. Intertidal community structure: experimental studies on the relationship between a dominant competitor and its principal predator, Oecologia, 15, 93-120.

Perrings, C. 1995. Biodiversity conservation as insurance, in T. M. Swanson, (Ed.), The economics and ecology of biodiversity decline. Cambridge University Press: Cambridge, UK.

Perrings, C. 1996. Ecological resilience in the sustainability of economic development, in S. Faucheux, D. Pearce, and J. Proops, (Eds.), Models of Sustainable Development. Edward Elgar: Cheltenham, UK.

Perrings, C. 1998. Resilience in the dynamics of economy-environment systems, Environmental and Resource Economics, 11, 503-520.

Perrings, C., Maler, K. G., Folke, C., Holling, C. S., and Jansson, B. O. 1995a. Introduction: framing the problem of biodiversity loss, in C. Perrrings, K. G. Maler, C. Folke, C. S. Holling, and B. O. Jansson, (Eds.), Biodiversity Loss. Cambridge University Press: Cambridge, UK.

Perrings, C., Maler, K. G., Folke, C., Holling, C. S., and Jansson, B. O., (Eds.). 1995b. Biodiversity Loss. Cambridge University Press: Cambridge, UK.

Perrings, C., Maler, K. G., Folke, C., Holling, C. S., and Jansson, B. O. 1995c. Unanswered questions, in C. Perrrings, K. G. Maler, C. Folke, C. S. Holling, and B. O. Jansson, (Eds.), Biodiversity Loss. Cambridge University Press: Cambridge, UK.

Perrings, C., and Walker, B. 1995. Biodiversity loss and the economics of discontinuous change in semiarid rangelands, in C. Perrings, K. G. Maler, C. Folke, C. S. Holling, and B. O. Jansson, (Eds.), Biodiversity Loss. Cambridge University Press: Cambridge, UK.

Ross, S. M. 1983. Introduction to Stochastic Dynamic Programming. Academic Press: San Diego, USA.

Ross, S. M. 1996. Stochastic Processes, $2^{\text {nd }}$ edition. John Wiley: New York, USA.

Ross, S. M. 1997. Introduction to Probability Models, $6^{\text {th }}$ edition. Academic Press: San Diego, USA.

Schindler, D. W. 1990. Natural and anthropogenically imposed limitations to biotic richness in freshwaters, in G. Woodwell, (Ed.), The Earth in Transition. Cambridge University Press: Cambridge, UK.

Solow, R. M. 1974. Intergenerational equity and exhaustible resources, Review of Economic Studies, 41, 29-46.

Turner, R. K. 1992. Speculations on weak and strong sustainability, CSERGE GEC Working Paper 92-26, CSERGE and UCL: London, UK. 
Walker, B. 1993. Rangeland ecology: understanding and managing change, Ambio, 22, 80-87.

Weninger, Q., and Strand, I. 1998. Regulating production time to control output: an application to a harvest technology. Unpublished manuscript, Utah State University.

Wolff, R. W. 1989. Stochastic Modeling and the Theory of Queues. Prentice-Hall: Englewood Cliffs, USA. 